\title{
Long-term Oncologic Outcome and Its Relevant Factors in Anal Cancer in Korea: A Nationwide Data Analysis
}

\author{
Hyuk Hur ${ }^{1, \star}$, Kyu-Won Jung, ${ }^{2, \star}$, Byung-Woo Kim², Chang-Mo Oh², Young-Joo Won ${ }^{2}$, Jae Hwan Oh${ }^{1}$, \\ Nam Kyu Kim ${ }^{1}$ \\ ${ }^{1}$ Korean Colorectal Cancer Study Group (KOCCS), The Korean Society of Coloproctology, Seoul, Korea \\ ${ }^{2}$ Cancer Registration and Statistics Branch, National Cancer Center, Goyang, Korea
}

Purpose: Anal cancer is a rare disease in Korea, and thus survival analyses are limited by small sample sizes. This study used the Korea Central Cancer Registry (KCCR) for a survival analysis and for assessing characteristics of anal cancer in a large sample of Koreans.

Methods: From the KCCR, data on 3,615 patients who were diagnosed and treated for anal cancer from 1993 to 2015 were retrieved. Clinicopathologic variables including age, sex, histological type, and Surveillance Epidemiology and End Results (SEER) stage were reviewed, and a survival analysis was performed according to these variables.

Results: The 5-year relative survival rate improved from $39.7 \%$ in $1993-1995$ to $66.5 \%$ in $2011-2015$. Squamous cell carcinoma was the most common and showed the highest survival rate. Males and older patients ( $\geq 40$ years and $\geq 70$ years) showed poor prognoses.

Conclusion: The survival rate for anal cancer in Korea has improved steadily over time. The characteristics related to survival were the histological type, sex, and age. These statistics will be fundamental for future Korean anal cancer research.

Keywords: Anus; Cancer; Survival; Korea; Registry

\section{INTRODUCTION}

Cancer of the anal canal or the perianal region is a rare malignant disease. It has been estimated that approximately 14,500 cases of anal cancer in women and 12,500 in men occurred in 2008 worldwide, but the incidence is increasing in high-income coun-

Received: February 7, 2019 • Accepted: July 17, 2019

Correspondence to: Nam Kyu Kim, M.D.

Division of Colon and Rectal Surgery, Department of Surgery, Yonsei University College of Medicine, Severance Hospital, 50-1 Yonsei-ro, Seodaemun-gu, Seoul 03722, Korea

Tel: +82-2-2228-2100, Fax: +82-2-313-8289, E-mail: namkyuk@yuhs.ac ORCID: https://orcid.org/0000-0003-0639-5632

Co-correspondence to: Young-Joo Won, Ph.D.

Cancer Registration and Statistics Branch, National Cancer Center, 323 Ilsan-ro, Ilsandong-gu, Goyang 10408, Korea

Tel: +82-31-920-2015, Fax: +82-31-920-2179, E-mail: astra67@ncc.re.kr ORCID: https://orcid.org/0000-0001-9861-6740

*Hyuk Hur and Kyu-Won Jung equally contributed as co-first authors.

(c) 2020 The Korean Society of Coloproctology

This is an open-access article distributed under the terms of the Creative Commons Attribution NonCommercial License (https://creativecommons.org/licenses/by-nc/4.0) which permits unrestricted noncommercial use, distribution, and reproduction in any medium, provided the original work is properly cited. tries [1]. Anal cancer is composed of various histological types, including squamous cell carcinoma, adenocarcinoma, and melanoma. Anal cancer in Korea is very rare accounting for $0.1 \%$ of the cancer incidence [2]. It occurs mostly in the elderly, especially those aged over 60 years.

Squamous cell carcinoma is known to be the most frequent type of anal cancer due to it being caused by the relatively common human papillomavirus (HPV). It is also found in immunosuppressed individuals (e.g., those infected by human immunodeficiency virus [HIV]) [3, 4]. Lifestyle factors such as smoking or a high number of sexual partners can increase the risk [5]. Highgrade anal intraepithelial neoplasia has been shown to progress to invasive anal cancer in HIV-positive or immunocompromised patients [6]. In Korea, the high-risk population with the above factors is increasing and the incidence of anal squamous cell carcinoma has been increasing over time [7].

The rare incidence and mixed nature of various histological types have limited anal cancer research, and the sample sizes of such studies are always small. The Korea Central Cancer Registry (KCCR) started as a nationwide, hospital-based cancer registry driven by the Ministry of Health and Welfare in 1980. Since 1999, the KCCR has grown to cover the whole population under the 
population-based cancer registry program. The KCCR thus provides sufficient quantity of data for the basic understanding of clinical features of Korean anal cancer. The purpose of the current study was to review the KCCR anal cancer data and to analyze survival according to various clinical features.

\section{METHODS}

From the KCCR, we extracted data on 3,615 patients with anal cancer who were diagnosed between 1993 and 2015. The primary cancer was first classified based on the International Classification of Disease for Oncology, 3rd edition [8], and then converted to the classification based on the International Classification of Diseases, 10th edition [9]. Histological types were categorized as (1) squamous cell carcinoma, (2) adenocarcinoma, (3) melanoma, (4) neuroendocrine tumor, (5) epithelial neoplasm, (6) sarcoma, and (7) others. Patient age, sex, and clinical data (such as tumor type and stage) were analyzed. This study was exempted from approval and informed consent by the Institutional Review Board of the Severance Hospital of the Yonsei University Health System.

The study time periods were split into 1993-1995, 1996-2000, 2001-2005, 2006-2010, and 2011-2015. For the period of 20112015, the Surveillance Epidemiology and End Results (SEER) stage system (local, regional, distant, and unknown) was used. The SEER local stage included tumors confined to the original organ (anus without invasion of adjacent organs, such as the vagina, urethra, bladder, and lymph-node metastasis). Regional disease included tumors with adjacent organ invasion or regional lymph-node metastasis. Distant disease included those with distant site metastasis. A comparison of SEER stages across TNM stages is shown in Supplementary Table 1. Patients were also grouped by age, with young patients defined as those in which the cancer developed prior to the age of 40 years, and advanced patients defined as those in which cancer developed after the age of 70 years. The survival rates of the above 2 age groups were respectively compared with that of the other age group (i.e., those between ages 40 and 70 years).

The 5-year relative survival rate (RSR), adjusted for the expected mortality of the general population of the same age and sex, was calculated using the Ederer II method [10]. The algorithm in SAS 9.3 (SAS Institute Inc., Cary, NC, USA) described by Dickman et al. [11] was applied for relative survival analysis, with minor modifications. Asymmetric observed survival confidence intervals (CIs) were made from log-transformed standard errors estimated using the Greenwood method. The RSR confidence limits were derived by dividing the observed survival limits by the corresponding expected survival rate.

\section{RESULTS}

\section{Histological Types and Stages of Anal Cancer}

Korean anal cancer incidences have increased annually from 354

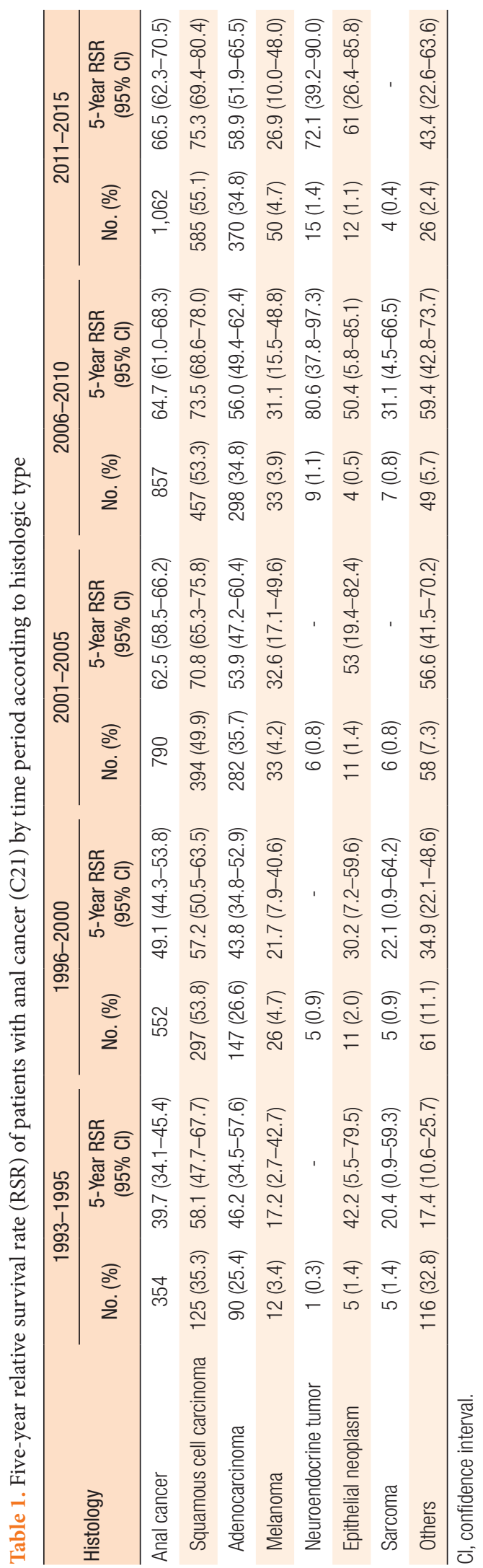


cases in 1993-1995 to 1,062 cases in 2011-2015. Squamous cell carcinoma was the most common histological type, comprising more than half of all cases from 1996 to 2015. Adenocarcinoma increased from $25.4 \%$ in $1993-1995$ to $34.8 \%$ in $2011-2015$. Melanoma, neuroendocrine tumors, epithelial neoplasm, and sarcoma form a small portion and show similar incidences during whole time period (Table 1; Figs. 1 and 2). The proportion of anal cancer in 2011-2015 with a regional stage designation across both sexes was $44.0 \%$; $33.5 \%$ were local stage tumors, and $9.7 \%$ were distant stage tumors. This order was evident among both male and female patients when analyzed independently (Table 2).

\section{Relative Survival Rates for Anal Cancer by Histological Type, Stage, and Patient's Sex and Age}

The 5-year RSRs by time period according to histological type are summarized in Table 1. The 5-year RSR increased from 39.7\% (95\% CI, 34.1\%-45.4\%) during 1993-1995 to 66.5\% (95\% CI, 62.3\%-70.5\%) during 2011-2015. Although improvements over

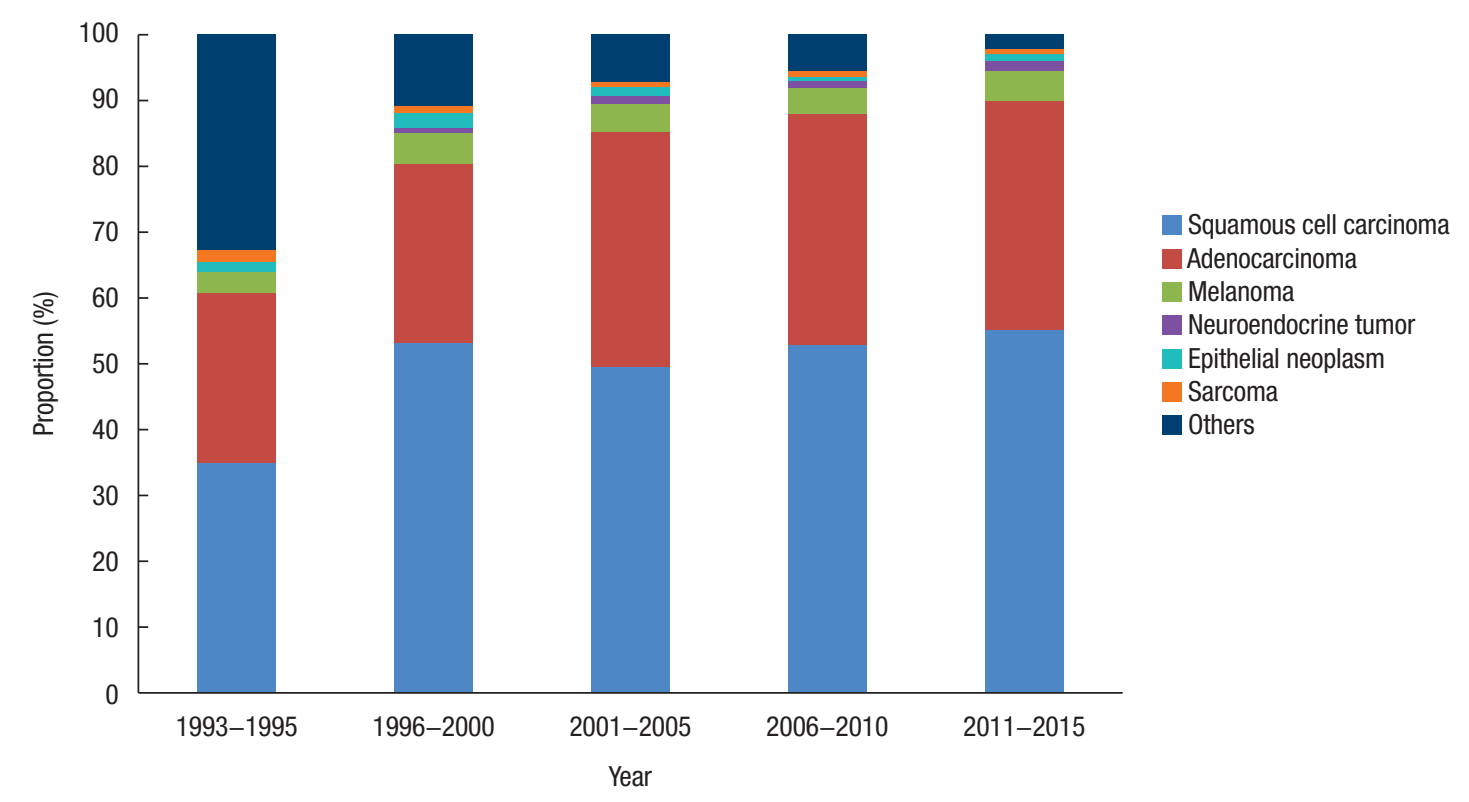

Fig. 1. Trends in the proportion of anal cancer by time period from 1993 to 2015 according to histologic type.

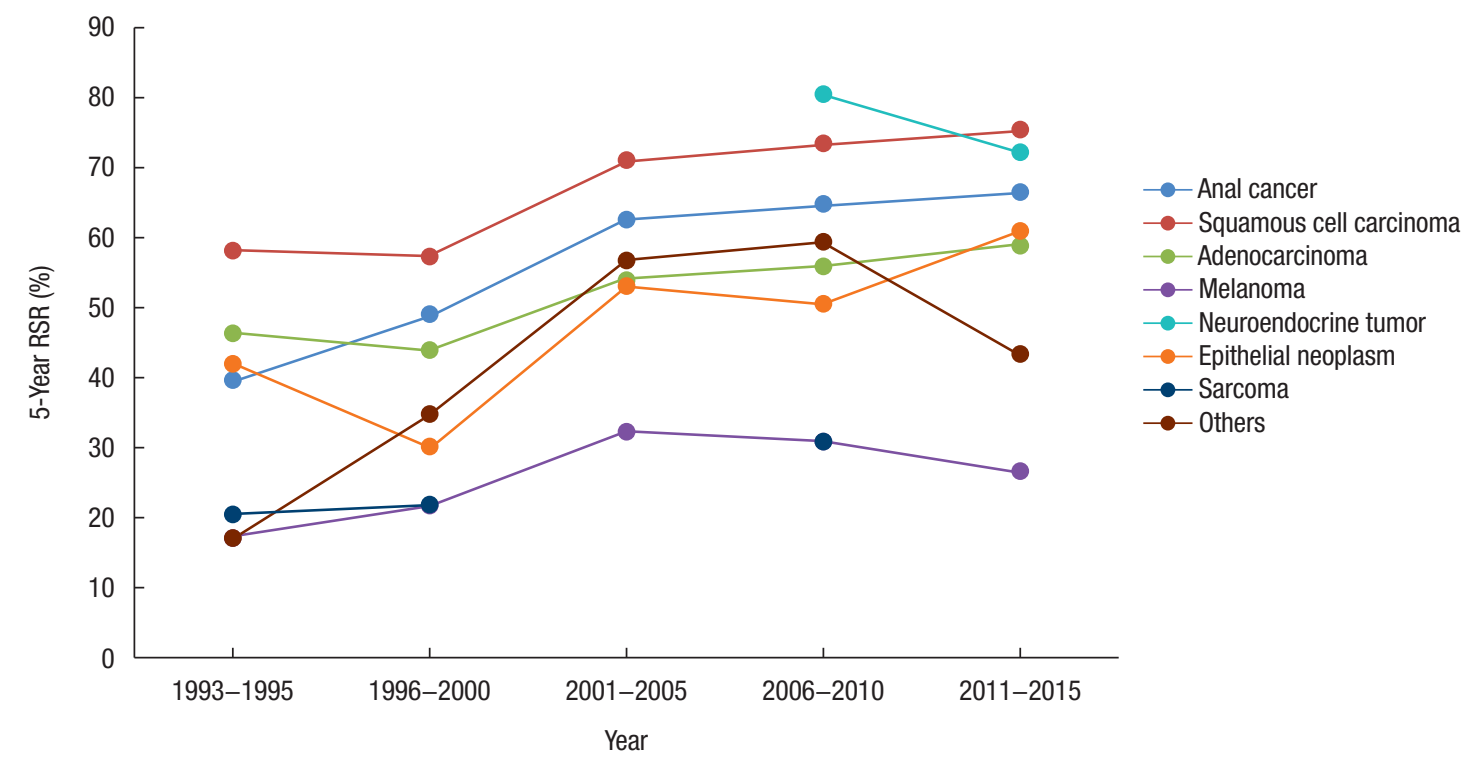

Fig. 2. Trends in 5-year relative survival rate (RSR) of patients with anal cancer by time period from 1993 to 2015 according to histologic type. 
Table 2. Five-year relative survival rate (RSR) of patients with anal cancer by sex according to SEER stage in 2011-2015

\begin{tabular}{|c|c|c|c|c|c|c|}
\hline \multirow{2}{*}{ SEER stage } & \multicolumn{2}{|c|}{ Both sexes } & \multicolumn{2}{|r|}{ Male } & \multicolumn{2}{|c|}{ Female } \\
\hline & №. (\%) & 5-Year RSR $(95 \%$ Cl) & No. (\%) & 5-Year RSR (95\% Cl) & No. $(\%)$ & 5-Year RSR $(95 \% \mathrm{Cl})$ \\
\hline Overall & 1,062 & $66.5(62.3-70.5)$ & 459 & $66.1(59.6-72.1)$ & 603 & $66.9(61.2-72.1)$ \\
\hline Local & $467(44.0)$ & 76.2 (69.7-81.8) & 207 (45.1) & $72.5(61.9-81.5)$ & $260(43.1)$ & 79.1 (70.7-85.8) \\
\hline Regional & $356(33.5)$ & $64.9(56.8-72.1)$ & $133(29.0)$ & $64.3(51.3-75.7)$ & $223(37.0)$ & $65.6(55.2-74.5)$ \\
\hline Distant & $103(9.7)$ & $35(24-46.5)$ & $47(10.2)$ & $33.2(17.6-50.3)$ & $56(9.3)$ & $36.6(21.8-52.0)$ \\
\hline Unknown & $136(12.8)$ & $61.3(50.4-70.9)$ & $72(15.7)$ & $70.3(56.1-81.6)$ & $64(10.6)$ & $50.1(33.1-65.6)$ \\
\hline
\end{tabular}

SEER, Surveillance Epidemiology and End Results; $\mathrm{Cl}$, confidence interval.

Table 3. Five-year relative survival rate (RSR) for patients with anal cancer aged $<40$ years and $\geq 40$ years according to SEER stage in 20112015

\begin{tabular}{lrcrrr}
\hline \multirow{2}{*}{ SEER stage } & \multicolumn{2}{c}{$<40$ Years } & & \multicolumn{2}{c}{$\geq 40$ Years } \\
\cline { 2 - 3 } \cline { 5 - 6 } & No. & $\begin{array}{c}5 \text {-Year RSR } \\
(95 \% \mathrm{Cl})\end{array}$ & & No. & $\begin{array}{c}5 \text {-Year RSR } \\
(95 \% \mathrm{Cl})\end{array}$ \\
\hline Overall & 38 & $79.5(60.9-90.0)$ & & 1,024 & $65.9(61.5-70.1)$ \\
Distant disease & 5 & $40.3(5.2-75.8)$ & & 98 & $34.4(22.9-46.5)$ \\
\hline
\end{tabular}

SEER, Surveillance Epidemiology and End Results; $\mathrm{Cl}$, confidence interval.

time occurred regardless of histological type, RSRs for melanoma were consistently the lowest (in all periods). The local stage showed a good 5-year RSR of 76.2\% in 2011-2015. The regional stage showed a lower 5 -year RSR of $64.9 \%$. The distant stage showed a poor 5-year RSR of $35 \%$. Female was related to better RSR in all SEER stages from 2011 to 2015 (Table 2). The 5-year RSRs were also compared among different age groups. The young-aged cancer group (less than 40 years) showed better survival compared to those over 40 years (Table 3 ). The patients aged 70 years or older with a distant stage had a worse RSR (Table 4).

\section{DISCUSSION}

This study demonstrated that anal cancer has increased during the past 20 years in Korea. The observed increased incidence occurred in all histologic types of anal cancer. In particular, the most common squamous cell carcinoma incidence has increased significantly. In the same time period, the 5-year RSR increased significantly in all histologic types according to the time period from 1993 to 2015. Survival was better for women, patients $<40$ years and $<70$ years.

The worldwide incidence of anal cancer has been increasingeither in both sexes or in women-in many populations, especially in the United States, Europe, and Australia [1]. In these populations, anal squamous cell carcinoma was substantially more common than other histological subtypes and was the main contributor to the increase in the anal cancer incidence. The incidence of anal squamous cell carcinoma is lower in Asia and Asian populations have seen little change. However, our study observed
Table 4. Five-year relative survival rate (RSR) for patients with anal cancer aged $<70$ years and $\geq 70$ years according to SEER stage in 20112015

\begin{tabular}{lrrrrr}
\hline \multirow{2}{*}{ SEER stage } & \multicolumn{3}{c}{$<70$ Years } & & \multicolumn{2}{c}{$\geq 70$ Years } \\
\cline { 2 - 3 } \cline { 5 - 6 } & No. & $\begin{array}{c}5 \text {-Year RSR } \\
(95 \% \text { Cl) }\end{array}$ & & No. & $\begin{array}{c}5 \text {-Year RSR } \\
(95 \% \text { Cl) }\end{array}$ \\
\hline Overall & 668 & $76(71.3-80.1)$ & & 394 & $48.7(40.4-56.9)$ \\
Distant disease & 57 & $37.8(23.0-52.6)$ & & 46 & $32.4(16.6-50.6)$ \\
\hline
\end{tabular}

SEER, Surveillance Epidemiology and End Results; $\mathrm{Cl}$, confidence interval.

an increasing incidence of anal squamous cell carcinoma over time. The reason for the increasing anal squamous cell carcinoma incidence rates in many populations is unclear, but is likely to reflect changes in the prevalence of environmental risk factors. Infection with HPV is an established risk factor for anal cancer [3]. Factors that lead to persistent anal HPV infection may thus be of great importance in the risk of developing anal cancer. These factors include concurrent cervical HPV infection and other HPVrelated anogenital diseases, receptive anal intercourse and probably tobacco smoking $[12,13]$. Furthermore, concomitant infection with HIV indirectly increases the risk of anal cancer by immunosuppression and increased replication of $\operatorname{HPV}[6,14]$. A number of studies have reported an association between tobacco smoking and anal cancer $[5,15]$. Immunosuppression following transplantation, and with some diseases, are associated with an increased risk of anal cancer [16]. In a previous report about characteristics and survival of anal cancer in Koreans [7], we observed the increasing incidence of anal squamous cell carcinoma, but the risk factors and the reason for the increasing incidence were not investigated in this study. An investigation of risk factors for the increasing incidence of anal squamous carcinoma in Korea is needed.

The treatment strategy for anal cancer mainly depends on the histological type. For squamous cell carcinoma, the most common type of anal cancer, chemoradiation therapy has been the standard treatment and has provided considerable outcomes [17]. The 5-year net survival increased during these 30 years from $63.4 \%$ to $72.7 \%$. Improved survival has also been observed in other countries [18]. These population-based results of real-world 
data, and the 5-year survival of patients who received curative chemoradiation therapy of $76.4 \%$, seem to be comparable with survival results obtained in clinical trials, and demonstrate the previously known dependency on disease stage [19]. During these 30 years, improvements in imaging have resulted in better staging, RT techniques have evolved with more precise radiation dose delivery and less risk of side effects [20], and clinical trials have investigated the optimal chemotherapy regimens in combination with RT $[19,21]$. Our study indicated that the survival rate for anal squamous cell carcinoma in Korea has also been improving since the early 1990s. However, there is no detailed information about the change in treatment modalities such as chemotherapeutic agents, radiotherapy techniques, and surgical procedures. More investigation and analyses are needed to know the exact reason for the increasing incidence and survival of anal squamous cell carcinoma.

Anal adenocarcinoma, the second-most common type, is considered similar to rectal cancer. The incidence of this type was reported to be stable in contrast to that of squamous cell carcinoma, which showed an increasing trend [22]. In contrast, our study shows the increasing incidence of anal adenocarcinoma according to the time period from 1993 to 2015. The recommended treatment strategy for this type of anal cancer is to follow that of low rectal cancer, which includes chemoradiation therapy followed by radical surgery. Not infrequently, this type is related to Crohn disease with long-lasting anal fistula [23].

The third-most common type, anal melanoma, is a rare disease in Korea. Although improving, the prognosis for melanoma remains poor. Anal melanoma is usually diagnosed at later stages and known to be refractory to chemoradiation therapy [24, 25]. Radical surgery remains effective in select cases and can achieve long-term survival [26, 27].

There were slightly more female patients with anal cancer in Korea and their prognoses were found to be better than those of male patients. In Korea, most female patients with solid organ cancers usually have a better prognosis [28]. Previous reports demonstrated that male patients with anal cancer might have worse outcomes after chemoradiation therapy especially for squamous cell carcinoma [29].

In this study, the advanced-aged patients (70 years or older) were found to have worse survival than the others. This observation may be attributed to less vigorous treatment in the advancedaged group. Recent studies, however, suggested that standard treatment could be well-tolerated and result in satisfactory oncological outcomes in elderly patients [30]. In Korea, where the proportion of the elderly population is growing, the treatment strategy for elderly patients with anal cancer needs to be assessed more carefully.

To summarize, the present study provides essential information regarding the clinical characteristics and survival of Korean patients with anal cancer.

\section{CONFLICT OF INTEREST}

No potential conflict of interest relevant to this article was reported.

\section{ACKNOWLEDGMENTS}

The authors thank the members of the Korean Colorectal Cancer Study Group for conception and design, data analysis and interpretation, and final approval of the manuscript. This study was supported by a grant from the National Cancer Center (NCC1610200).

\section{SUPPLEMENTARY MATERIAL}

Supplementary Table 1 can be found via https://doi.org/10.3393/ ac.2019.07.17.

\section{REFERENCES}

1. Islami F, Ferlay J, Lortet-Tieulent J, Bray F, Jemal A. International trends in anal cancer incidence rates. Int J Epidemiol 2017;46: 924-38.

2. Jung KW, Won YJ, Kong HJ, Lee ES; Community of PopulationBased Regional Cancer Registries. Cancer Statistics in Korea: incidence, mortality, survival, and prevalence in 2015. Cancer Res Treat 2018;50:303-16.

3. De Vuyst H, Clifford GM, Nascimento MC, Madeleine MM, Franceschi S. Prevalence and type distribution of human papillomavirus in carcinoma and intraepithelial neoplasia of the vulva, vagina and anus: a meta-analysis. Int J Cancer 2009;124:1626-36.

4. Machalek DA, Poynten M, Jin F, Fairley CK, Farnsworth A, Garland SM, et al. Anal human papillomavirus infection and associated neoplastic lesions in men who have sex with men: a systematic review and meta-analysis. Lancet Oncol 2012;13:487-500.

5. Daling JR, Madeleine MM, Johnson LG, Schwartz SM, Shera KA, Wurscher MA, et al. Human papillomavirus, smoking, and sexual practices in the etiology of anal cancer. Cancer 2004;101:270-80.

6. Berry JM, Jay N, Cranston RD, Darragh TM, Holly EA, Welton ML, et al. Progression of anal high-grade squamous intraepithelial lesions to invasive anal cancer among HIV-infected men who have sex with men. Int J Cancer 2014;134:1147-55.

7. Park HC, Jung KW, Kim BW, Shin A, Won YJ, Oh JH, et al. Characteristics and survival of Korean anal cancer from the Korea central cancer registry data. Ann Coloproctol 2013;29:182-5.

8. Adams R. Surveillance of anal canal cancers. Surg Oncol Clin N Am 2017;26:127-32.

9. Aggarwal A, Duke S, Glynne-Jones R. Anal cancer: are we making progress? Curr Oncol Rep 2013;15:170-81.

10. Ederer F, Heise H. Instructions to IBM 650 programmers in processing survival computations. Methodological note No. 10. End Results Evaluation Section. Bethesda (MD): National Cancer In- 
stitute; 1959.

11. Paul W Dickman [Internet]. Stockholm (Sweden): Karolinska Institutet [2012 Dec 7]. Available from: http//www.pauldickman. com.

12. Stier EA, Sebring MC, Mendez AE, Ba FS, Trimble DD, Chiao EY. Prevalence of anal human papillomavirus infection and anal HPV-related disorders in women: a systematic review. Am J Obstet Gynecol 2015;213:278-309.

13. Shvetsov YB, Hernandez BY, McDuffie K, Wilkens LR, Zhu X, Ning L, et al. Duration and clearance of anal human papillomavirus (HPV) infection among women: the Hawaii HPV cohort study. Clin Infect Dis 2009;48:536-46.

14. Crum-Cianflone NF, Hullsiek KH, Marconi VC, Ganesan A, Weintrob A, Barthel RV, et al. Anal cancers among HIV-infected persons: HAART is not slowing rising incidence. AIDS 2010;24:53543.

15. Tseng HF, Morgenstern H, Mack TM, Peters RK. Risk factors for anal cancer: results of a population-based case--control study. Cancer Causes Control 2003;14:837-46.

16. Pernot S, Terme M, Zaanan A, Tartour E, Weiss L, Taieb J. Immunity and squamous cell carcinoma of the anus: epidemiological, clinical and therapeutic aspects. Clin Res Hepatol Gastroenterol 2014;38:18-23.

17. Oblak I, Petric P, Anderluh F, Velenik V, Fras PA. Long term outcome after combined modality treatment for anal cancer. Radiol Oncol 2012;46:145-52.

18. Soeberg MJ, Rogers K, Currow DC, Young JM. Trends in incidence and survival for anal cancer in New South Wales, Australia, 1972-2009. Cancer Epidemiol 2015;39:842-7.

19. Ajani JA, Winter KA, Gunderson LL, Pedersen J, Benson AB 3rd, Thomas CR Jr, et al. Fluorouracil, mitomycin, and radiotherapy vs fluorouracil, cisplatin, and radiotherapy for carcinoma of the anal canal: a randomized controlled trial. JAMA 2008;299:191421.

20. Kachnic LA, Tsai HK, Coen JJ, Blaszkowsky LS, Hartshorn K, Kwak EL, et al Dose-painted intensity-modulated radiation therapy for anal cancer: a multi-institutional report of acute toxicity and response to therapy. Int J Radiat Oncol Biol Phys 2012;82:
153-8.

21. James RD, Glynne-Jones R, Meadows HM, Cunningham D, Myint AS, Saunders MP, et al. Mitomycin or cisplatin chemoradiation with or without maintenance chemotherapy for treatment of squamous-cell carcinoma of the anus (ACT II): a randomised, phase 3, open-label, $2 \times 2$ factorial trial. Lancet Oncol 2013;14: 516-24.

22. Nelson RA, Levine AM, Bernstein L, Smith DD, Lai LL. Changing patterns of anal canal carcinoma in the United States. J Clin Oncol 2013;31:1569-75.

23. Ogawa H, Haneda S, Shibata C, Miura K, Nagao M, Ohnuma S, et al. Adenocarcinoma associated with perianal fistulas in Crohn's disease. Anticancer Res 2013;33:685-9.

24. Nilsson PJ, Ragnarsson-Olding BK. Importance of clear resection margins in anorectal malignant melanoma. Br J Surg 2010;97:98103.

25. Meguerditchian AN, Meterissian SH, Dunn KB. Anorectal melanoma: diagnosis and treatment. Dis Colon Rectum 2011;4:63844.

26. Che X, Zhao DB, Wu YK, Wang CF, Cai JQ, Shao YF, et al. Anorectal malignant melanomas: retrospective experience with surgical management. World J Gastroenterol 2011;17:534-9.

27. Choi BM, Kim HR, Yun HR, Choi SH, Cho YB, Kim HC, et al. Treatment outcomes of anorectal melanoma. J Korean Soc Coloproctol 2011;27:27-30.

28. Jung KW, Park S, Shin A, Oh CM, Kong HJ, Jun JK, et al. Do female cancer patients display better survival rates compared with males? Analysis of the Korean National Registry data, 2005-2009. PLoS One 2012;7:e52457.

29. Bentzen AG, Guren MG, Wanderås EH, Frykholm G, Tveit KM, Wilsgaard T, et al. Chemoradiotherapy of anal carcinoma: survival and recurrence in an unselected national cohort. Int J Radiat Oncol Biol Phys 2012;83:e173-e180.

30. Lestrade L, De Bari B, Montbarbon X, Pommier P, Carrie C. Radiochemotherapy and brachytherapy could be the standard treatment for anal canal cancer in elderly patients? A retrospective single-centre analysis. Med Oncol 2013;30:402. 